\title{
Insulin, food restriction and the extension of lifespan: the mechanism of longevity
}

\author{
Ettore Bergamini, Gabriella Cavallini, Alessio Donati and Zina Gori \\ Centro di Ricerca di Biologia e Patologia dell'Invecchiamento dell'Università di Pisa, via Roma 55, 56126 Pisa, Italy \\ (Correspondence should be addressed to E Bergamini; Email: ebergami@ipg.med.unipi.it)
}

Dötsch et al. reported in this journal (1) on Blüher and co-worker's evaluation of the $18 \%$ increase in the lifespan of fat-specific insulin receptor knockout (FIRKO) mouse (2). As early as 3 months of age, these mice maintained a body weight approximately $20 \%$ below the body weight of their control littermates. The reduction in body weight was caused by an approximately $60 \%$ reduction of fat tissue. Interestingly, their appetite was not reduced, resulting in the food intake being equivalent to that of the control animals. As a consequence, food intake related to body weight exceeded that of the controls by more than $50 \%$ (3). The conclusion was that a reduction of fat mass without caloric restriction can be associated with increased longevity in mice, possibly through effects on insulin signalling.

Dötsch et al. highlighted that Blüher et al. fell short of explaining the mechanism of longevity in their FIRKO mice, because they speculated about a reduction in the generation of oxygen-free radicals $(4,5)$ or a mechanism involving insulin-like growth factor-I (IGF-I) signalling but unfortunately they did not provide any data regarding that hypothesis. We would like to mention here that a possible explanation of prolongation of lifespan by caloric restriction or defective insulin signalling has already been published (see ref. 6, Fig. 3): lower insulin levels or activity may increase autophagy and lysosomal proteolysis $(7,8)$, the anti-ageing cell repair mechanism which improves disposal of altered membranes and cellular organelles, and cell housekeeping $(6,9)$. This explanation is in line with recent genetic findings which demonstrate that autophagy genes are required for normal dauer morphogenesis and lifespan extension in Caenorhabditis elegans (10).

The good news is that the beneficial effect on longevity could be obtained by drugs, without any genetic manipulation: a decrease in free fatty acid (FFA) plasma levels by the lifelong administration of antilipolytic drugs to fasted rats may retard the age-related changes in biomarkers of ageing that are known to correlate with life expectancy $(11,12)$.

It is conceivable that in the FIRKO mice, the $50-70 \%$ reduction in fat mass throughout life might be associated with a decrease in the production and plasma levels of FFA.

The antilipolytic drug for the purpose of the Pharmacological Intensification of Suppression of Ageing (PISA) (this name was kindly suggested by Dr George
Martin, Seattle, WA, USA) is licensed for human use as a hypolipidaemic agent (Acipimox). From a practical point of view, the treatment might open a way to make more people likely to adhere to an anti-ageing regimen of dietary restriction otherwise too intensive to be endurable over an extended period involving much of human life (13).

\section{References}

1 Dötsch J, Meißner U \& Wolfgang R. Prolonged lifespan by defective insulin signalling? European Journal of Endocrinology $2003 \mathbf{1 4 8}$ 489-490.

2 Blüher M, Kahn BB \& Kahn CR. Extended longevity in mice lacking the insulin receptor in adipose tissue. Science $2003299572-574$.

3 Blüher M, Michael MD, Peroni OD, Ueki K, Carter N, Kahn BB, et al. Adipose tissue selective insulin receptor knockout protects against obesity and obesity-related glucose intolerance. Developmental Cell 20023 25-38.

4 Hamilton ML, Van Remmen H, Drake JA, Yang H, Guo ZM, Kewitt $\mathrm{K}$ et al. Does oxidative damage to DNA increase with age? PNAS 200198 10469-10474.

5 Lee SS \& Ruvukun G. Longevity: don't hold your breath. Nature $2002418287-288$.

6 Bergamini E, Cavallini G, Donati A \& Gori Z. The anti-ageing effects of caloric restriction may involve stimulation of macroautophagy and lysosomal degradation, and can be intensified pharmacologically. Biomedicine $\mathcal{E}$ Pharmacotherapy 200357 203-208.

7 Mortimore GE \& Poso AR. Intracellular protein catabolism and its control during nutrient deprivation and supply. Annual Review of Nutrition 19877 539-564.

8 Klionsky DJ \& Emr SD. Autophagy as a regulated pathway of cellular degradation. Science 2000290 1717-1721.

9 Del Roso A, Vittorini S, Cavallini G, Donati A, Gori Z, Masini M et al. Ageing-related changes in the in vivo function of rat liver macroautophagy and proteolysis. Experimental Gerontology 2003 38 519-527.

10 Melendez A, Talloczy Z, Seaman M, Eskelinen EL, Hall DH \& Levine B. Essential role of autophagy genes in dauer development and lifespan extension in C. elegans. Science $2003 \mathbf{3 0 1}$ 1387-1391.

11 Cavallini G, Donati A, Gori Z, Pollera M \& Bergamini E. The protection of rat liver autophagic proteolysis from the age-related decline co-varies with the duration of anti-ageing food restriction. Experimental Gerontology $200136497-506$.

12 Dolfi C, Bergamini E, Carresi C, Cavallini G, Donati A, Maccheroni M et al. The age-related accumulation of dolichol in rat liver may correlate with expectation of life. Biogerontology 2003 4 113-118.

13 Masoro E. Challenges of Biological Aging. New York: Springer, 1999.

Received 10 October 2003

Accepted 13 October 2003 